Florida International University FIU Digital Commons

$3-27-2018$

\title{
Queering The Clown Prince of Crime: A Look at Queer Stereotypes as Signifiers In DC Comics'The Joker
}

Zina Hutton

zhutt001@fiu.edu

DOI: $10.25148 /$ etd.FIDC006550

Follow this and additional works at: https://digitalcommons.fiu.edu/etd

Part of the Modern Literature Commons, and the Other Film and Media Studies Commons

\section{Recommended Citation}

Hutton, Zina, "Queering The Clown Prince of Crime: A Look at Queer Stereotypes as Signifiers In DC Comics' The Joker" (2018). FIU Electronic Theses and Dissertations. 3702.

https://digitalcommons.fiu.edu/etd/3702 


\section{FLORIDA INTERNATIONAL UNIVERSITY}

Miami, Florida

\section{QUEERING THE CLOWN PRINCE OF CRIME:}

A LOOK AT QUEER STEREOTYPES AS SIGNIFIERS IN DC COMICS' THE

\section{JOKER}

A thesis submitted in partial fulfilment of the

requirements for the degree of

MASTER OF ARTS

in

ENGLISH

by

Zina Hutton

2018 
To: Dean Michael R. Heithaus

College of Arts, Sciences and Education

This thesis, written by Zina Hutton, and entitled Queering the Clown Prince of Crime: A Look at Queer Stereotypes as Signifiers in DC Comics' The Joker, having been approved in respect to style and intellectual content, is referred to you for judgment.

We have read this thesis and recommend that it be approved.

$\overline{\text { Jason Pearl }}$

Heather Blatt

Ana Luszczynska, Major Professor

Date of Defense: March 27, 2018

The thesis of Zina Hutton is approved.

Dean Michael R. Heithaus

College of Arts, Sciences and Education

Andres G. Gil

Vice President for Research and Economic Development and Dean of the University Graduate School

Florida International University, 2018 


\author{
ABSTRACT OF THE THESIS \\ QUEERING THE CLOWN PRINCE OF CRIME: \\ A LOOK AT QUEER STEREOTYPES AS SIGNIFIERS IN DC COMICS' THE \\ JOKER \\ by \\ Zina Hutton \\ Florida International University, 2018 \\ Miami, Florida \\ Professor Ana Luszczynska, Major Professor
}

The goal of this thesis is to explore the way heterosexism and homophobia are present in the coding that has created an implied and monstrous queer identity for the Joker, present in many versions of the character over the past forty years. Through close readings of several of the Joker's most iconic appearances, queer theory texts, and analytical essays on pop culture, this paper will analyze the use of queer signifiers present in the comics and the way that these portrayals of the Joker are rife with harmful and heterocentric perceptions of what comic creators have seen as necessary signifiers for queerness. Additionally, I will be using knowledge gleaned from my own preexisting work with fan and cultural studies in order to talk about the way that this portrayal of the Joker has been developed within fandom/fan communities and how it is continually replicated in superhero media. 


\section{TABLE OF CONTENTS}

CHAPTER

PAGE

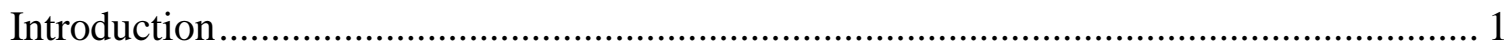

Defining Queerness and Queer-Coding ................................................................ 6

The Joker Doesn't Want to Rev His Harley - Signifying Misogyny ............................. 11

The Joker as "Queer Threat" - The Relationship Between Batman and the Joker .......... 23

Queer Clowning - The Joker, "Dark camp", and Performativity ................................. 31

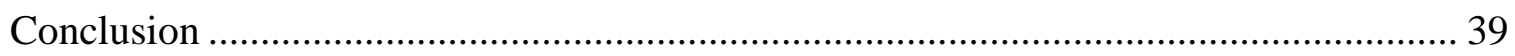

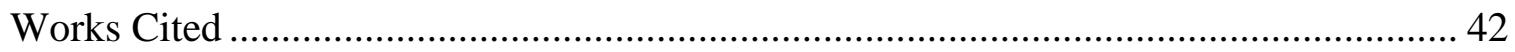




\section{Introduction}

In a 1991 interview with Christopher Sharrett, Batman writer Frank Miller described his Joker (in The Dark Knight) as "a homophobic nightmare"1 essentially because he represented everything that Bruce Wayne/Batman despises - he is diametrically opposed to everything that the Joker represents according to Miller. ${ }^{2}$ This includes the characters' sexuality and gender identity. Where Batman represents a hypermasculine and heterosexual male power fantasy, the Joker is a constantly shifting character who appears to inhabit a more fluid take on gender and whose interest in Batman is repeatedly seen as questionable. When Sharrett later calls the Joker "the only gay character in the book" after bringing up several gay signifiers that Miller's take on the character possesses, Miller doesn't disagree. In fact, Miller continues to reiterate the notion of the Joker appears to hold the Joker's existence as a supposed "homophobic nightmare" and the character being gay in his work as simultaneous positives. Miller goes on to say that "[it] is very much a part of the Batman/Joker mythos. It's always been there, I just spelled it out a little more plainly" (Sharrett 37-38). The notion that there has somehow always been a queer interest in Batman on the Joker's behalf and that it explains their behaviors toward one another is complicated to unpack. However, the idea

\footnotetext{
${ }^{1}$ This phrase refers to the Joker as being a nightmare of a homophobic person, not that the Joker is a homophobic character.

${ }^{2}$ Miller describes the Joker as "Not so much a Doppelganger [for Batman] as an antithesis, a force for chaos. Batman imposes his order on the world, he is an absolute control freak. The Joker is Batman's most maddening opponent. He represents the chaos Batman despises, the chaos that killed his parents" (36), positioning the characters as diametrically opposed to one another in a way that can encompass the characters' sexualities.
} 
of the Joker being a queer ${ }^{3}$ parallel to Batman is fascinating because of what such a claim says about modern day "nerd culture" and its ever present, toxic masculinity-fueled homophobia.

The Joker, DC Comics' most recognizable villain, has spent much of his almost eighty-year existence engaged in an unending game of cat-and-mouse with Batman, one of the company's flagship heroes. The characters' relationship is one that comes packed with an undercurrent of queerness in the signifiers that writers and artists attach to the Joker. Several of the Joker's most familiar and iconic stories (i.e., Alan Moore's The Killing Joke, Scott Snyder and Greg Capullo's Batman: Death of the Family, the recent Lego Batman film, and Grant Morrison and David McKean's Arkham Asylum: A Serious House on Serious Earth) show the character as taking a homoerotic interest in Batman, making repeated attempts to center himself in Batman's life. These texts will be integral to exploring the way that the Joker has historically been encoded with stereotypes about queer masculinity that are then used to create a pervasive perception of the Joker as a villain whose queerness serves as a subtextual threat to Batman - and his fans.

The Joker is one in a long line of pop culture villains whose queer-coding appears to come from a place of unquestioned and casual homophobia and that requires serious assessment as the Joker has set the mold for multiple other villains. As superhero comics increase their impact on other forms of media (such as young adult novels, video games, and films), it is important to analyze the way that media creators working in these industries construct narratives around characters like the Joker whose identity comes with

\footnotetext{
${ }^{3}$ Throughout this paper, I will be using the word "queer" alongside theorist's usage of "gay" and "homosexual" (and related terminology) as "queer" is more inclusive and can be expanded to
} 
loaded messages about what queerness looks like for their audiences. Messages that serve as signifiers - signals about something intended to reach the audience. The most relevant example is that of the queer signifier as it is supposed to denote queerness and/or a queer identity in a character. These signifiers may take the form of literal signs such as the handkerchief code of the seventies or the use of certain kinds of slang (i.e., ballroom and queen slang as seen in the documentary Paris Is Burning). In this context, a queer signifier is supposed to signal the character's queerness. Signifiers need not be stereotypes, but may take the form of stereotypes in media that are homophobic and/or anti-queer.

Queer readings of the Joker come about because he pays Batman a little too much attention, because he wears makeup, and because he's seen as incapable of and uninterested in having relationships with women. Additionally, the Joker is read as queer because he chases after Batman - when in the same vein, queer readings of the Batman usually don't center on his relationship with the Joker or their unending game of cat and mouse. This distinction matters because this relationship, while having a mirror reflection of each characters' focus represented, only acknowledges the Joker's interest as one that could be read as queer. Batman's fixed following of the Joker is seen as pure, just, and absolutely heterosexual while the Joker's fixation on Batman is presented as deviant. There are a few things that remain constant over the Joker's years of film appearances: his green hair, the rictus grin he wears at all times, and, as a result of a closer look at his character, the appearance of queer signifiers in his characterization. These queer signifiers for the Joker include a full face of makeup, the way that he invades the space of male characters (Batman is a constant, but the 2016 Suicide Squad film had a scene 
where the Joker climbed into another male character's lap in order to intimidate him), and the way that he talks/his mode of speech. ${ }^{4}$ Nerd culture is rife with frightening takes on the Joker that neatly coincide with appearances that are clearly intended to code him as possessing a non-normative sexuality and gender identity. ${ }^{5}$ Whether the character's monstrosity - frequently highlighted by the use of the aforementioned queer signifiers in conjunction with images of horrific and casual violence that work to bridge a connection between the character's presumed sexuality and his evil -- is supposed to glean a reaction from Batman or from fans, it is always connected implicitly to the character's queercoding and how it poses as a threat to Batman's hypermasculinity.

This paper will cover several incarnations of the Joker that are queer-coded thanks to the use of stereotypes that are implicit in the text(s) and the way that these portrayals of the character come complete with the baggage of cis male writers and what they see as necessary signifiers for queerness. While the character has existed for almost eighty years, few major works of scholarship have looked at the way that his gender performance and sexual identity seem purposefully crafted in order to push the idea of queerness as a form of monstrosity. Queer monstrosity hinges on the idea that "anything that opposes or lies outside the ideological status quo [is] intrinsically monstrous and unnatural" (Benshoff 2). Historically, many films and texts have used a queer identity and/or queerness as a subtle, but present signifier that tells audiences that they're looking at a monster (Benshoff 15). This use of queerness to denote monstrosity - the true

\footnotetext{
${ }^{4}$ This refers to the way that some writers choose to shift between Joker dialogue that either tends toward a mincing type of dialogue or a flowery, almost Wildean type of speech.

${ }^{5}$ The Joker is never more frightening in his various incarnations when he is assigned queer coding via these signifiers.
} 
development of a queer monstrosity - is present throughout a majority of the Joker's existence. He's the Joker's "bad twin" (Medhurst 160) and part of what makes the Joker Batman's evil opposite is the fact that the queer signifiers in the text are used to imply that his queer sexuality is a bad thing. This thesis will primarily rely on a framework built from existing queer theory texts and close readings of several iconic Joker stories in order to analyze the way that the Joker's perceived sexuality has evolved over the years and relies on or presents harmful stereotypes about said sexuality that portray queer men as violent, deviant monsters. Additionally, I will be using techniques from my own preexisting work with queerness in fan and cultural studies in order to talk about the way that the "Joker as queer threat" is developed within fandom/fan communities and continually replicated in the canon text ${ }^{6}$ as well as shared with the wider world outside of the rather insular comic fandom and industry. This thesis will explore the way heterosexism and queerphobia - towards queer men - work in the queer-coding that has created an implied and monstrous queer identity for the Joker. This coding is present in nearly every single version of the character within the past forty years, and yet is not talked about by comics culture and their communities unless it is as the butt of a joke. I believe that this thesis will help forge the start of many conversations in academia and fan spaces as the desire for properly portrayed queer representation frequently comes up against the industry's inability to address the Joker's constant characterization.

\footnotetext{
6 Within the comics industry, "canon" largely holds a different meaning from typical literary views. Anything published within comics is canon as in "it exists and impacts the characters" rather than a definitive "this is the only approved way to view the characters". Canon in comics fan communities and the industry that spawned it are always official, but sometimes they may no longer be relevant.
} 


\section{Defining Queerness and Queer-Coding}

Before talking in depth about the ways that the Joker is written as a queer-coded character whose characterization comes across through implicit and often stereotypical ideas about what queer masculinity looks like and how it is performed, we must first look at defining what "queer" and "queer-coding" mean in the context of this paper and the character it focuses on. Broad definitions of the term "queer" abound, with Queer: A Graphic History pointing out that "queer" can be a noun, an adjective, and a verb depending on the person using it and why it's being used (Barker 7). Many theorists that work on queer theory don't think that queerness can be defined at a specific level - or at all - due to the way that the field and term appear to encompass multitudes. ${ }^{7}$ Queer theorist Nikki Sullivan, in her seminal work A Critical Introduction to Queer Theory, claims that trying to define what queer is "a decidedly un-queer thing to do" (Sullivan 43). Defining "queer" in any firm way is perceived as "un-queer" because it can be seen as serving to reinforce hegemonic power structures by establishing a queer/un-queer binary that positions some people/things/experiences as inherent or automatic outsiders. Typically, the predominant definitions for "queer" and "queerness" are so broad as to be useless in discussions about specific narrow topics because the broadness makes it impossible to wield these definitions carefully and specifically in analysis. Queer, to many theorists, refers simply to anything (i.e., a person, action, sexuality) that goes against established and dominant social norms. For example, in his book Saint Foucault,

\footnotetext{
7 This refers to David Halperin's claims that anyone marginalized for their gender or sexual identity can claim queerness, therefore causing the term to encompass the entire potential communities and the way that their members perform and otherwise express their identities.
} 
David Halperin writes that, "Queer is by definition whatever is at odds with the normal, the legitimate, the dominant" (Halperin 62). Many theorists whose study falls underneath the umbrella of queer theory hesitate to define the term queer or even their actual field, beyond how it refers to people, sexualities and the like, that constitute a nebulous Other that goes against heteronormative society. For the purposes of this paper, I will be using a definition of "queer" that positions it as a form of performativity that is not centered on a hetero- and/or cis- centric expression of sexuality or identity, which draws on Benshoff's definition of queerness as something that goes beyond "all such categories based on the concepts of normative heterosexuality and traditional gender roles to encompass a more inclusive, amorphous, and ambiguous contra-heterosexuality" (Benshoff 5).

In order for creators - both in film and in the comics industry - to get queer characters past censors alongside approval and a widespread audience, they turned to queer-coding. Queer-coding, as a negative, was primarily and purposefully used in the creation of villains. Villains such as Anthony Perkins' Norman Bates (Psycho), Raul Silva (Skyfall), and numerous Disney characters (The Lion King's Scar, The Little Mermaid's Ursula, Pocahontas' Governor Radcliffe) are all examples of villains being coded as queer. These villains were assigned queerness - via stereotypes centered on supposedly effeminate or hyper stylish fashion, predominantly antagonistic relationships with women, and their style of speech - as queerness was seen to be one more thing that made villains appear to be depraved and out of bounds of a presumably heteronormative society (Benshoff 69) as queer monstrosity has been a staple of horror since the late nineteenth and early twentieth centuries (Benshoff 20). 
Queer-coding, as a concept, facilitates discussion about how characters have been subtextually queered in their narratives without any text supporting their queerness and how some characters are assigned these queer signifiers without also being given a canonical and confirmed queer identity to go along with it. Queer-coding, something that hinges on the use of signifiers and nudges to the audience, is rarely something that leads to queer representation. Queer-coding relies on signifiers where aspects of a character's behavior, performance, and personality are used to create room for the audience to read characters and situation as queer. In his book Making Things Perfectly Queer:

Interpreting Mass Culture, Alexander Doty writes that "[q]ueer readings aren't "alternative" readings, wishful or willful misreadings, or "reading too much into things" readings. They result from the recognition and articulation of the complex range of queerness that has been in popular culture texts and their audiences all along" (1997 16). The queerness exhibited by the Joker - in and out of relation to the Batman - fits neatly into the "complex range of queerness" Doty refers to. Additionally, queer-coding often leads to the very queer readings of the character that will be interrogated in this text as the Joker's history is unfolded.

In "Becoming the Monster: Queer Monstrosity and the Reclamation of the Werewolf in Slash Fandom" author Jaquelin Elliott introduces the relationship between queerness and monstrosity and how coding in these cases can lead to a queer "queer monstrosity" (91). Elliott writes that this "queerness of monstrosity", "feels to many queer fantasy fans as one more space without room for them" (102) as these queer-coded characters (monsters, villains, and the like) are frequently kept apart from the main narratives - as are queer fans. The spaces that the Joker inhabits consist of comic book 
stores, internet forums, and social media websites where marginalized people particularly women and queer people - are explicitly not welcome. In the introduction to Alexander Doty's Flaming Classics: Queering the Film Canon, he writes that, “(stereo) typed coding of queerness and straightness does exist in both dominant and queer cultures" (2002 5). Stereotyped coding is evident in the way that audiences associate certain behaviors and appearances along a dichotomous line of thinking that only sees “obvious" queerness or straightness alone. Doty's work on queering mass media and modern popular culture provides a background to pull from when looking at the separate ways that the Joker has been aligned with signifiers that are meant to inspire an association with common stereotypes of binary notions of gender and sexuality which the various manifestations of the Joker themselves subverted - such as what gay men look and behave like.

The origins of "queer-coding", a core feature of my thesis argument and a negative form of pseudo-representation commonly associated with villainous or otherwise detestable characters in modern mass media, can be traced back to the early 1930s and the creation of the Motion Picture Production Code (henceforth referred to via the more familiar, colloquial "Hays Code" ${ }^{8}$ ) and the Comics Code Authority close to twenty years later. In essence, the goal of the Hays Code was to inhibit the production of films that could "lower the moral standards of those who see it" (Erwin 18). The Hays Code was created in order to rehabilitate Hollywood's image following several high-

\footnotetext{
${ }^{8}$ Named after Will H. Hays who was the president of the Motion Picture Producers and Distributors of America at the time the code was first enacted.
} 
visibility scandals and the threat of lawsuits and censorship ${ }^{9}$ and was supposed to minimize audience exposure to sexuality, violence, and disrespect for authority figures such as priests, police, and the government (Wright 182), noted representatives of hegemonic institutions that have historically done work to further marginalized people in the name of continuously upholding a status quo that therefore needs heteronormativity and misogyny alive for it to thrive. While queer films prior to 1934 were not a paragon of progressive representation, ${ }^{10}$ the Hays Code meant that all form of queerness had to go undercover if it was to be present at all. As Erwin writes, "Homosexuality itself had to be "coded" in such a way that any depiction could be read on the surface as a heterosexual narrative. Just enough homosexual signifiers were included in the subtext to allow audiences open to a gay reading to be rewarded with a wink of understanding, while those looking for a heterosexual reading were blissfully ignorant" (Erwin 1). Like the Hays Code, the Comics Code Authority was put into action as a method of policing a largely self-governed institution following a public scandal. In the case of the comic book industry, the scandal came in the form of writer and psychologist Frederic Wertham's controversially titled Seduction of the Innocent - a book that claimed comic books of the period were actively harmful to the wellbeing of children (Weldon 45). Both the Comics Code Authority and the Hays Code prohibited their respective industries from showing

\footnotetext{
${ }^{9}$ Scandals such as the alleged rape and murder of Virginia Rappe by Fatty Arbuckle and the threat of censoring films with controversial themes sparked the creation of this code.

${ }^{10}$ Queer characters were present in limited ways and were largely presented via caricature and explicit stereotypes.
} 
similar types of content, with a strict focus on banning on sexual identity and expression that these organizations determined to be deviant in some way.

The Joker Doesn't Want to Rev His Harley - Signifying Misogyny

In Paul Dini and Bruce Timm's 1994 one-shot comic The Batman Adventures: Mad Love, there is a scene where the character Harley Quinn interrupts the Joker's plotting with an attempt to seduce him only to be literally thrown out of their hideout after he rebuffs her (Dini and Timm 27). Not only does the Joker show no sexual or romantic interest in the character in this book, he frequently uses her as a tool for his schemes, as set dressing, or as someone to blame when his schemes fail. Additionally, the Joker has another use for women: he sees them as potential victims on his path to his goal of centering himself in Batman's life. In his essay “The Sissy Boy, The Fat Ladies, and The Dykes: Queerness and/as Gender in Pee-Wee's World," in Making Things Perfectly Queer, Alexander Doty confronts the stereotype that, "gay men hate and dismiss women because they don't want to have sex with them" (1997 190). It is a stereotype that appears to be reinforced by the Joker's repeated interactions with female characters - most specifically his bisexual, on and off "love interest" Harley Quinn.

This section will look at the way that queer readings of the Joker cannot exist without considering his violence and condescension towards women. In Mad Love and several episodes of the animated Batman series of the early Nineties, the Joker's outright loathing for women and his violence towards them is used as a clear signifier of his misogyny. This part of the paper, partially a close reading of Paul Dini and Bruce Timm's Mad Love, will look at how sexualized violence against female characters 
(Hutton) at the hands of the Joker serves to connect the Joker's subtexual queerness to stereotypes about queer men's misogyny. On the subject of queer misogyny, Alexander Doty writes that:

the "one-size-fits-all" approach to male misogyny that Modleski and others employ when critiquing Paul Reubens's work with women characters is not very sensitive to how the particular position of gay men within patriarchy has been constructed in relation to concepts of "woman" and the "feminine." (1997 86)

"Male misogyny" as a signifier of queerness is one of the recurring character traits that is associated with the Joker and that has been connected with him for a majority of his existence. Throughout the Joker's decades-long history, the character has never had real romantic relationships. His current "love interest", Harley Quinn, is more of a punching bag than a person that he cares about. The writers' consistent use of misogyny as an integral aspect of his character serves to reinforce stereotypes of queer men as women haters (Doty 1997 131) and a significant portion of this section will go to analyzing the way that this specific stereotype, when taken to this extreme, has been embedded in the character from this period onward. The use of misogyny - primarily towards Harley Quinn - is important to look at because the comics have used the Joker's negative reactions to women as an integral and unquestioned part of his character - often used both for the aforementioned queer signifying and as part of a joke.

Aside from Harley Quinn (first introduced in the 1992 Batman the Animated Series episode "Jokers Favor") and a brief, but unexplained flirtation with the White Rabbit in a 2011 issue of Detective Comics, the Joker has little interest in female 
characters. While a disinterest in female characters alone is not in and of itself a signifier of queerness - as Batman, despite being in multiple relationships with female characters across the decades, rarely shows interest in them - what the Joker does do to women calls back to the erroneous idea that queer men hate women more than non-queer men do because their misogyny is supposedly born out of jealousy - either of what women have or what they are. In Theodore Price's book Hitchcock and Homosexuality: His 50-year Obsession with Jack the Ripper and the Superbitch Prostitute - A Psychoanalytic View, Price writes that:

$[\mathrm{M}]$ any of Hitch's Jack the Ripper figures are homosexuals. And in Hitchcock films - something that must never be overlooked - is a convention that all homosexuals (or nearly all) hate women on general principles, or, at the very least, are hostile to women because they cannot make love to them effectively. (Price xiii)

Here, Price points out that a stereotype associated with gay men is that they dislike women because they cannot satisfy one another. In Alexander Doty's chapter on Alfred Hitchcock's Psycho in Flaming Classics, he describes this misogyny as "another classical cultural stereotype of homosexuality" (2002 164), indicating that the jealousy that these gay men are assumed to have for straight women is played out via violence towards women in these pieces of media. This stereotype, as Price and Doty frame it in their respective works, takes the disinterest and violence against women present in some queer-coded characters (such as Hitchcock's Norman Bates and the Joker) and uses it as a marker of queerness. 
It is also a stereotype that, as Doty suggests in Making Things Perfectly Queer, does not acknowledge that the way that queer men are stereotyped as "woman haters" has more to do with how these queer men are treated as "lacking" masculinity than it does their problems with women (1997 86). In the Batman canon, the Joker is infamous for the controversial violence that he has inflicted on two female characters: Harley Quinn and former Batgirl, Barbara Gordon. For this section I will also evaluate how that the Joker interacts (or has interacted) with these two female characters, in order to argue that,, particularly in the case of the on-and off- again relationship that the character has with Harley Quinn, the character's violence towards women falls in line with the argument that queer(-coded) male characters tend towards a stereotype of misogyny and violence. Additionally, a further goal of this section is to dissect the use of the way that these two Joker stories do nothing to dismantle the trope, but instead succeed in reinforcing harmful ideas about queer men and the relationships that they have with women.

Harley Quinn's first appearance is as the Joker's female assistant in Joker's Favor, the only one of his minions that can be trusted to help him carry out his plan against Gotham City Commissioner James Gordon on a night when the city is celebrating him. Dressed in the red and black Harlequin suit that would become her trademark, the character primarily operates as a cheerleader, supporting the Joker's desire to crash the event. The Joker is shown basking in Harley's adoration in her opening scene, but aside from that, he shows no other interest in the character aside from her value as a minion. For much of the animated series' run, Harley Quinn primarily serves as a "hype-man" or 
head minion for the Joker. ${ }^{11}$ Then came the Paul Dini and Bruce Timm's The Batman Adventures: Mad Love. The comic, published in 1994, focuses on the unequal and violent relationship between the Joker and Harley Quinn and the way that Harley as a character was influenced by her relationship with the Joker. Three things are significant about Mad Love that render it incredibly necessary to discussions about the Joker's queer-coding in the comic canon: the way that the Joker manipulates Harley Quinn into becoming his henchwoman, his disinterest in participating in a sexual relationship with Harley, and the violent climax of Mad Love.

What Mad Love made canon is the fact that the Joker manipulated an already mentally fragile Harleen Quinzel into becoming Harley Quinn. The character originally worked as the Joker's psychiatrist in Arkham Asylum before the Joker effectively managed to turn her into his loyal henchman, brainwashing her and remaking her in his own image. As the Joker's Harley Quinn, Quinzel's characterization and personality preJoker is wiped away and replaced by a fluid character who attempts to always be what (she thinks) the Joker needs her to be. Most of the time, that is. As mentioned at the start of this section, an iconic scene in Mad Love shows Harley Quinn trying to interact with the Joker while the latter character is busy putting together one good plan to effectively and finally take Batman down once and for all. At one point in the scene Harley Quinn is dressed in a short, see-through nightgown, and after she attempts to get the Joker's

\footnotetext{
11 There are a few exceptions to this such as the Batman the Animated series episode "Harley's Holiday" where Harley is released from Arkham Asylum and "Harlequinade" where the character appears to be working with Batman against the Joker before she betrays Batman.
} 
attention several times (One time asking him "Don't ya wanna rev up your Harley”), he shows increasing exasperation with the character before dumping her outside of their lair. So soon after her initial introduction, Harley's relationship with the Joker in Mad Love becomes one where the romance is one-sided. The Joker's reaction to Harley Quinn's sexual and romantic interest in Mad Love is to reject it because it is ultimately unsatisfying for him and therefore useless. He has no time for Harley Quinn or her affections because he is too busy trying to figure out the perfect plan for his end goal of capturing and killing Batman. This disinterest is atypical in the hypermasculine medium of superhero comics where explicitly heterosexual heroes and villains alike are frequently tempted into and implied to have offscreen sexual encounters with their wives, girlfriends, and one-night stands.

In comics, queer heroes and villains typically have their intimacy limited to kisses and entirely off screen sexual moments (they don't even get the "fade to black" motif that many of these "Teen+" comics adopt in these situations for classic male/female couples). The Joker's absolute lack of interest in Harley's sexuality reads as a joke on both of their expenses because he does not want her and she is unwanted despite being portrayed as a (heterosexual) sexual ideal in skimpy clothing. The rejection of Harley Quinn is atypical for the genre, yet nevertheless the Joker rarely shows sexual or romantic interest in Harley Quinn. Outside of the 2017-2018 alternate Earth series Gotham White Knight, the Joker has never had implicit or explicit sex with Harley Quinn and largely treats her as a thorn in his side. This disinterest in a character people widely refer to as his girlfriend is one of the ways that Mad Love and other Batman pieces that focus on the Joker code him as queer via stereotypes. 
Next, I am going to cover how Mad Love and The Killing Joke take an aspect of the stereotypical queer male misogyny to an extra violent level due to the way that a tacitly queer-coded Joker enacts violence against the female characters in each work. In Mad Love, the Joker reacts with jealousy to Harley Quinn's accomplishments while in The Killing Joke, he attacks former Batgirl Barbara Gordon specifically so that he can inflict trauma on and gain attention from her father James. As discussed above, one aspect of the stereotypical misogyny assigned to queer men and queer-coded male characters is the belief that these queer men have a disinterest in women that eventually mutates into anger at their inability to satisfy these women or to be satisfied themselves. In the case of the Joker, this disinterest turns to anger and then violence.

In Mad Love, the Joker begins to get increasingly fed up with his inability to capture and kill the Batman. No matter the plan that he devises, something always happens to foil his plans, sometimes even before the Joker can enact them. One such plan is called "The Death of a Hundred Smiles" and involves Batman being dropped into a piranha tank where the last thing he will see before he is eaten are the "smiles" on the piranhas' faces. The Joker decides that the plan will not work because piranha mouths simply do not work that way, and, to him, the lack of smiling fish faces would not be funny. Later in the comic, Harley Quinn attempts to do what the Joker could not and winds up successfully capturing Batman and improving upon his plan. The Joker's response to Harley's success is to slap her and throw her out of a window, leaving her bruised and broken body lying on the ground. For much of Mad Love and other comics that showcase the Joker's relationship with Harley Quinn, violence that the Joker enacts against Harley Quinn is primarily used to generate laughs or for shock value (Taylor 83). 
However, at its core, the Joker's significant moment of violence in Mad Love stems from his jealousy of Harley and how, by capturing Batman, she succeeds in achieving a form of intimacy with him that the Joker cannot have. As a woman who gains access to Batman in a way that he has been denied, Harley Quinn is subject to the Joker's jealousy at his inability to get to his object of desire. This results in him lashing out at Harley Quinn for doing what he cannot in successfully dominating the man that he desires (Taylor 85).

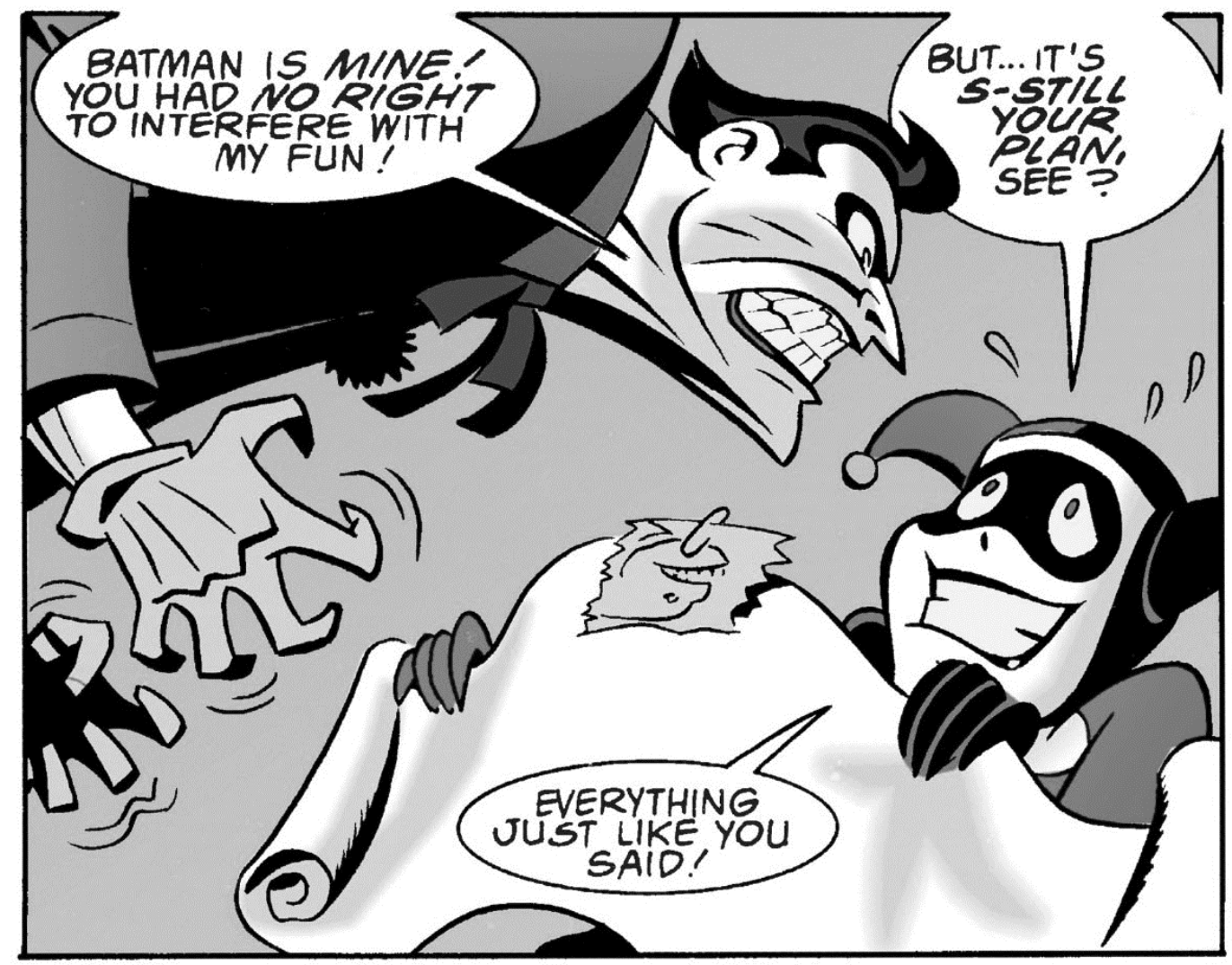

Figure 1 - The Joker menaces Harley Quinn for daring to try to take Batman/the "honor" of killing Batman away from him in Mad Love.

However, the violence that a queer-coded Joker commits against women is not limited to Mad Love and can be seen in the 1988 graphic novel Batman: The Killing Joke where the Joker's violence against Barbara Gordon is implied to have a sexual assault- 
component that has largely been unaddressed both by the higher ups at DC comics and fans of the Joker (Brooker). While a majority of the gendered violence in The Killing Joke remain offscreen, images of Barbara's naked body and comments that the Joker makes to her father in the graphic novel provide the heavy-handed implication that she was sexually assaulted -- either directly by the Joker or by his henchmen. In a panel following the shooting, the audience is shown a panel of the Joker reaching for Barbara's shirt and unbuttoning it. The next time that we see Barbara from this scene, it is in the form of photographs where she is naked and shown in different and sexualized positions (Moore and Bolland 23). Additionally, one of the reasons that The Killing Joke serves as an example of misogyny (and a potential queer misogyny) is the simple fact that while violence against Barbara Gordon is used to get to her father Police Commissioner James Gordon $^{12}$ the comic focuses primarily on the Joker's violence and male reactions to his violence.

While the gendered violence in The Killing Joke seems at odds with the idea of the Joker as a queer-coded character, I argue that it in fact confirms my theory that the predominantly male writers working on the character have used it as one more way to tie the Joker's disinterest in women to violence and then use both in order to have the character read along lines of queer stereotypes while behaving in ways that inadvertently showcase the texts' misogyny. The Killing Joke tries to present the violence against Barbara Gordon as incidental (i.e., the Joker would have shot any of Jim Gordon's family that answered the door, therefore his actions towards Barbara cannot be misogynistic).

\footnotetext{
${ }^{12}$ And Batman to a lesser extent.
} 
However, while the initial act of violence is one that can sustain this interpretation, nothing about the violence against Barbara really is not misogynistic. The Joker shoots her low in the abdomen - possibly, her uterus (Moore 41). He strips her, posing her nude body as he takes photographs to later show her father.

Here is why the Joker's treatment of women is more indicative of a heterosexual / heterocentric misogyny rather than queer male misogyny: without fail, the creators behind the stories are largely heterosexual men who perceive depictions of gratuitous violence against women as a necessary feature of their work and view violent misogyny as a necessary aspect of the Joker's character. ${ }^{13}$ Additionally, the fact that Barbara is injured and potentially sexually assaulted across the course of the graphic novel does not matter to the overarching plot. ${ }^{14}$ That would make this story about someone other than the Joker, about something other than the Joker's fascination with both Batman and James Gordon. Neither James Gordon nor Batman actually or explicitly get revenge for the violence committed against Barbara, leaving him alive and her minimal character arc unfulfilled as the graphic novel's focus lands on their interactions with the Joker. In The Killing Joke, the use of violence comes across as something similar to Alfred Hitchcock's Psycho where the queer-coded villain is violent towards women either because of a relationship with a woman/women that has gone poorly ${ }^{15}$ or an interest in or anger

\footnotetext{
${ }^{13}$ The Killing Joke is consistently referenced as one of the greatest Joker stories ever told and received well enough to receive two separate adaptations.

${ }^{14}$ Alan Moore specifically asked editor Len Wein for permission to write Barbara as one of the Joker's victims in The Killing Joke.

${ }^{15}$ The Killing Joke gives the Joker a tragic backstory in the death of his wife during the dissolution of their relationship (Moore and Bolland 23)
} 
towards a male character that is otherwise uninterested in them (Doty 2002 182). While other texts have developed Barbara Gordon beyond The Killing Joke and flesh out her reaction to the trauma undergone in this graphic novel, it was not Alan Moore's original intentions to use the act of violence against Barbara Gordon to do anything other than shock the audience (Felton) ${ }^{16}$ - by codifying the Joker as both a sexual pest/predator and frame him as further frightening because of the brutality of the violence that he commits. In both The Killing Joke and Mad Love, we see a form of the Joker that uses violence against women as both a means to an end and as a mode of self-expression for his own desires. In Mad Love, the Joker's violence towards Harley Quinn is supposed to be hilarious. The audience is supposed to laugh at scenes of Harley Quinn being thrown off of the Joker's desk. Additionally, even when that comic's climax has him throw her out of a window, the graphic novel still ends with her pining after him in a way that is supposed to be humorous even as it exemplifies the abusive cycle of their relationship and the dehumanizing way that he treats her. In The Killing Joke, Barbara Gordon is at the core of some of the most horrific violence in the comic, however the comic is not about her. In the 2016 animated adaptation of The Killing Joke, a large amount of the film's focus lands on the sexual relationship that Barbara Gordon has with Batman (fabricated for the adaptation) in addition to graphically displaying the violence against her in the name of traumatizing and torturing her father figure. Over twenty years after

\footnotetext{
${ }^{16}$ In "“The Killing Joke' Doesn't Deserve Credit for the Creation of Oracle” author Kieran Shiach says that "Alan Moore has gone [on] record saying that Baraba's trauma was an afterthought. Quite famously, he approached his editor Len Wein with the idea, seeking approval, and Wein responded with 'Yeah, okay, cripple the bitch"'.
} 
the first printing of The Killing Joke, Barbara Gordon's trauma is still not about her and continues to center the male characters in the narrative.

These texts appear to use the Joker's violence against women as one way to codify him as queer, using images of violence - stemming from the character's jealousy of Harley Quinn's success with Batman and the desire to gain "straight" male attention by hurting Barbara Gordon - alongside historical and stereotypical views about of queer men and the relationships that they have with women. Unfortunately, these widely republished comics are recommended to children and young adults reading superhero comics for the first time because of their interest in these works' female characters. Marginalized readers - in this case, readers who are queer and/or women - are thus faced with these problematic texts deemed iconic, which constantly inspire new work even though they show a queer-coded character committing violence against women and receiving no punishment or censure by the end of the book. What is harmful about stories like Mad Love and The Killing Joke being seen as iconic stories for the Joker is that these works uncritically portray violence against women used in conjunction with the character's implied queer identity. The Joker does not want to rub his Harley, but unfortunately what he does want to do to women is terrible - as is the way that his actions are under-addressed in the texts. 
The Joker as "Queer Threat" - The Relationship Between Batman and the Joker In Scott Snyder and Greg Capullo's Death of the Family, ${ }^{17}$ the Joker appears with makeup on what remains of his face - a traditionally "feminine" signifier" - and interacts with the various members of the "Batfamily" in ways that are clear signifiers of the Joker's queer interest and identity (i.e., the text has the Joker comment on the scent another male character is wearing while invading his personal space (Capullo and Synder 54). Additionally, the Joker's goal in Death of the Family is to disrupt the family that Batman has created for himself in order to center his jealous self in the other man's life. His anger in the book comes from Batman's repeated rejection and so it inspires his revenge. As a result of the jealousy present in this work and other example works in the genre that present the Joker as a queer threat, this section of the paper aims to analyze why this characterization and threat are present in works such as The Killing Joke, Death of the Family, and Arkham Asylum: A Serious House On Serious Earth. Additionally, we will be looking at the way that the Joker's presence as a queer threat are linked with the fear of a "gay Batman" as a result of the character's relatability and the fan fear of a hypermasculine figure either "turning" on his established audience or revealing parts of these fans that they otherwise deny. The immediate "queer threat" that the Joker represents to Batman (and has since Frank Miller's take on the character in the late Eighties) is a fear that the character will attempt to force himself and his supposed sexuality onto Batman. The "queer threat" that the Joker presents to Batman and to the hypermasculine and heteronormative nerd culture around comics is that he will somehow

\footnotetext{
${ }^{17}$ Batman Volume 2, 2012.
} 
change Batman's sexuality, destroying a figure that these fans can see as their ideal male fantasy.

First, we will look at the way that the Joker's consistent game of cat and mouse and the conclusion it almost comes to in Death of the Family represents a fear of a queer Other infiltrating heteronormative society and is one leg of a fictional relationship that has existed for decades. The complicated relationship between the Joker and Batman and the threat that the Joker poses to Batman's loved ones - did not appear for the first time in 2012 with Death of the Family. It has several notable precursors throughout comics dating back to the late Eighties with the character's earliest successes in disrupting the Batman's family. In 1987's Batman \#408, the Joker shoots the current Robin, Dick Grayson. In 1988’s “A Death in the Family” (Batman \#426-29), the Joker beats the second Robin, Jason Todd, to death. Then in 2008, Heath Ledger's Joker appears in The Dark Knight where a key plot point of the film involves on the Joker attempting to remove distractions to the Batman's life in the form of Rachel Dawes and Harvey Dent, Batman's love interest and best friend, respectively. Attacking or kidnapping one of the members of Batman's found family is frequently confirmed as the best way to get the character's attention and killing these characters would be a way for the Joker to have Batman focus entirely on him (Devine). ${ }^{18}$

\footnotetext{
${ }^{18}$ In the documentary Necessary Evil, Peter Tomasi said that:
}

The Joker feels that the family that Batman has built around him all these years ... is dragging him down. He says, "These people are draining your soul. These other members of the Bat family, they're sucking the life out of you. I'm your friend. I wanna make you be the best that you can be, ... so that we can both have a relationship that we could enjoy for so many years, ... without these knuckleheads on the side constantly draining you. And so I'm gonna take care of them for you. And I'm going to wipe out all these family members, ... so you can be free of their encumbrance." 
At the end of Moore and Bolland's Batman: The Killing Joke, there are a series of narration boxes that provide an internal monologue for Batman that signifies the complicated and dangerous relationship between the two characters - and alludes to the way that the relationship will probably end:

Hello. I came to talk. I've been thinking lately... about you... About me. About what's going to happen to us, in the end. We're going to kill each other aren't we? Perhaps you'll kill me... Perhaps I'll kill you. Perhaps sooner... Perhaps later (Snyder and Capullo 48).

In this quote, Batman shows that he views the Joker as a character that sees him for who he is and that shows that the relationship between the characters is far from one-sided. In this genre of fiction, villains and heroes often have intensely intimate relationships that span decades. Despite that, no hero-villain relationship outside from the one that the Joker and Batman share with one another has this level of intimacy - this acceptance of death at each other's hands.

In Grant Morrison and Dave McKean's Arkham Asylum: A Serious House on Serious Earth, the Joker is portrayed as a queer man who serves as a threat to heterosexual male characters. In particular, the Joker serves as a queer threat both to Batman and to the fanbase that sees him as a heteromasculine ideal. In the notes attached to the script for Arkham Asylum ${ }^{19}$, In the history of queerness in Hollywood - especially

This quote refers to the way that the Joker explicitly states that he sees Batman's found family is dragging him down and keeping him from focusing on the Joker.

${ }^{19}$ This script was included in the back of the 25th Anniversary re-release of the original graphic novel. 
as it related to monsters - ideas about and understanding of queerness comes through a framework of male homosexuality and the fear that such sexuality has inspired in a heteronormative society (Benshoff 6). In the introduction of this paper, I referenced an interview response from Frank Miller where he described the Joker in The Knight Returns as “a homophobic nightmare” (Sharrett 37), and Morrison’s Joker stands to reinforce the use of the Joker as a "homophobic nightmare" to Batman/the reader stems from a belief that queer men are a threat to the supposedly dominant heterocentric patriarchy that Batman represents - perhaps recalling a part of themselves that they would like to deny.

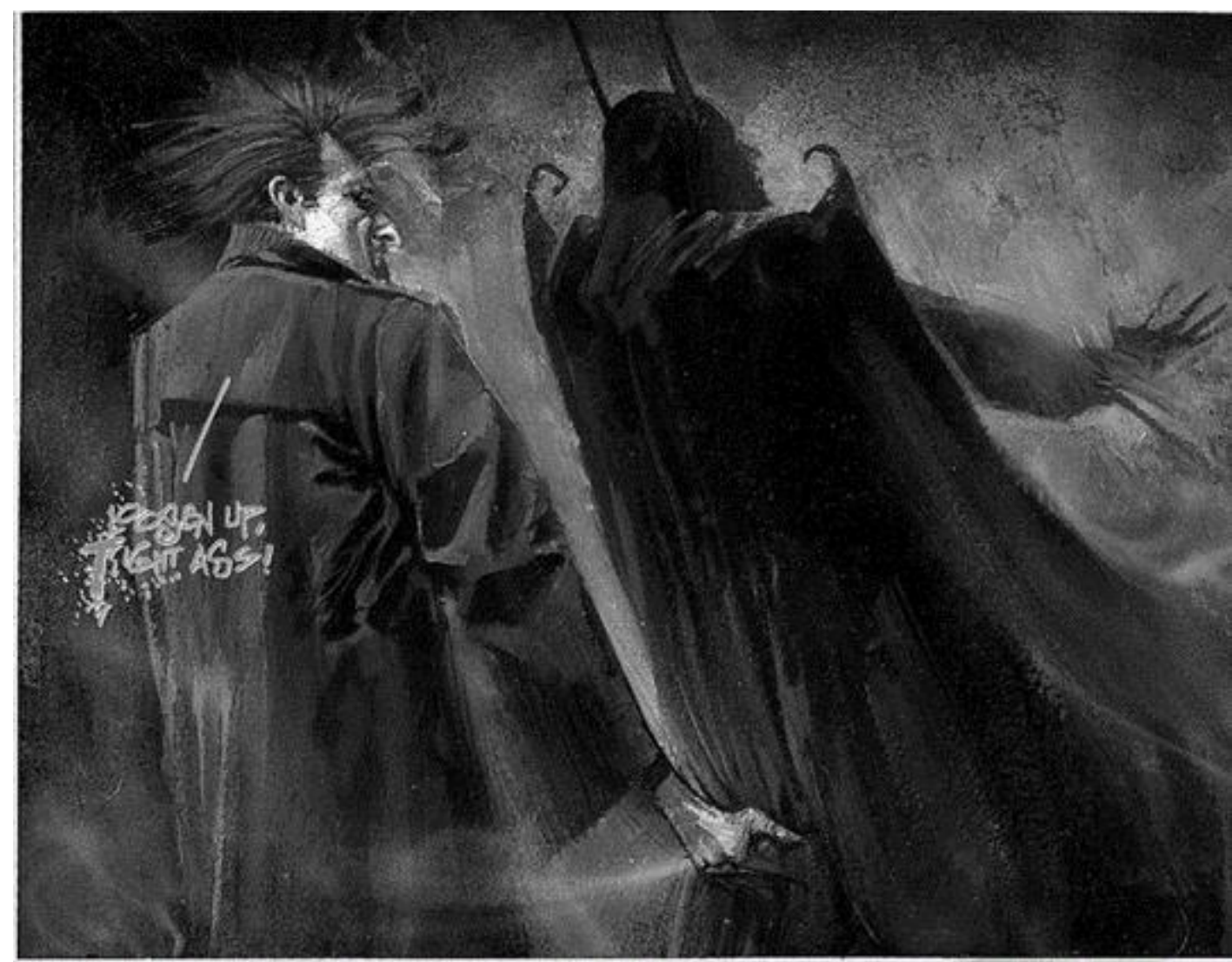

Figure 2 - From Arkham Asylum. The Joker tells Batman to "loosen up, tight ass" after grabbing him. 
The Joker in Morrison's Arkham Asylum is, as we see in the description from Morrison's notes, a figure that exists to embody a non-binary gender identity and a fluid sexuality. For example, what makes Morrison's queer-coded Joker emblematic of nerd fears of a queer Joker is the way that he interacts with Batman - and the way that Batman's reactions to the Joker's behavior mimics the way that queer men are frequently mistreated in media and real life. Batman, like many other heroic male figures in speculative fiction, is a hypermasculine, heterosexual male fantasy who reacts badly at the presence of queerness that attempts to "tempt" him just by existing. As seen in Figure Two, when he and the Joker first physically interact in Arkham Asylum, Batman calls the Joker a "Filthy degenerate" after the other character grabs his rear end and demands that he "loosen up, tight ass!" (Morrison 25). Batman's response to being sexually harassed by his nemesis is not just anger at having his personal space infringed upon, but at the Joker being the one to do it. ${ }^{20}$

Batman comes loaded with a few of the same signifiers that the Joker has been assigned - misogyny laden relationships and interactions with women and his singleminded focus on the Joker in particular. However, they are not taken in the same way by creators and fans alike. This raises a question: If the Joker is queer-coded in part because of his interest in Batman being read as a queer one, why then is Batman not queer-coded

\footnotetext{
${ }^{20}$ Historically, Batman has reacted differently to infringements in his space from female villains. Talia al Ghul, who Morrison himself wrote assaulting him to conceive a child, is received far differently than the Joker's infringements.

Additionally, in the script in the back of the twenty-fifth anniversary of the graphic novel's release, Grant Morrison writes of the scene visible in Figure Two that "the Joker's effeminate actions are thus seen to be quite deliberate", equating the Joker's sexual harassment the threat it poses to Batman with effeminate behavior and queerness (Morrison 25, script)
} 
for showing his own obsessive interest in the Joker? In Scott Snyder and Greg Capullo's Death of the Family, there is a scene of internal dialogue that stands as an excellent example of the way that analysis of Batman's various texts simply point out that Batman is just as obsessed with the Joker as the Joker is with him and how interpretations of queer-coding should go both ways. In his internal monologue, Batman tells himself that: And the reservoir was the site of your first fight with Joker. Your first real battle with him. It was where you first saw him, really saw him, for who he was. Where you understood what you were facing in him. And it was where he saw you back. (Snyder and Capullo 48)

This quote is relevant in the way that it calls back to a recurring theme in the Batman's various interactions in the cat-and-mouse game that he plays with the Joker: when pressed, Batman frequently acknowledges the fact that he believes that the Joker is one of the few people he interacts with that understands him. More so than his allies, the Joker is often treated as a partner or Batman's dark other half. This quote seems to point out, the Joker is the one character who truly understands why Batman has devoted himself to fighting crime and why he cannot stop, therefore he cannot stay away from the Joker. Like the Joker, Batman rarely shows any sort of long-term, intimate, and positive interest in women. Most of Batman's most long-lasting and intimate relationships are with other male characters (in particular Superman, various Robins, and of course, the Joker). Additionally, Batman's historic queer-coding also comes from his interactions with a male character and can be traced back to a comment from Frederic Wertham's Seduction of the Innocent where he says that Batman and Robin's relationship looks like the "wish dream of two homosexuals living together" (Wertham 190). Hardcore Batman fans 
simply ignore the coding that comes along with the character either because it appears to "ruin him" (Weldon 205) for them, something which stems from homophobia.

Fears of a queer Joker somehow "infecting" Batman are, in part, due to the way that Batman fans see the character as relatable, identifying with the character because he is "merely" a human in a world populated by superheroes (Weldon 3). Even though his true superpowers are wealth and whiteness ${ }^{21}$ the character is accessible to nerds who cannot possibly see themselves identifying with Superman or Wonder Woman because of their inhuman power. Conveniently, Batman is also seen as relatable because of the fact that many of his most ardent fans see him as a ladies' man as the hypermasculine ideal he represents can only be heterosexual. With that imagined relatability fueling fan love of Batman, it is no surprise then, that Batman fans - many of whom also champion the Joker as one of the genre's greatest villains - are unlikely to interact with interpretations of the Batman and the Joker as queer or where the relationship is reciprocated. Texts which utilize the Joker's single-minded fixation on Batman to portray him as automatically more frightening than other villains ${ }^{22}$ never appear to realize that Batman's reciprocated fixation carries a similar weight. In Death of the Family, Batman is just as obsessive as the Joker is, but interpreting that fascination in a way that provides a queer reading - of a queer (if repressed) Batman - is one that nerd culture cannot stand.

\footnotetext{
${ }^{21}$ In the introduction to The Caped Crusade, Weldon references the way that despite Batman's unrealistic wealth (which makes his heroics possible), fans can't help seeing him as an everyman character. In the first trailer for 2017 blockbuster Justice League, when the Flash asks Batman what his superpower is, Batman responds by saying "I'm rich".

${ }^{22}$ Harvey Dent and Thomas Elliot are two of Bruce Wayne/Batman's childhood friends who have intimate and long-lasting relationships with him even into their villainhood and yet they don't have the relationship that the Joker has with Batman. They're never portrayed as threatening to Batman's masculinity or frightening to the audience because of their potential or implied sexuality.
} 


\section{In The Caped Crusade: Batman and the Rise of Nerd Culture, Glen Weldon}

points out that Batman's fanbase does not have room for readings of a queer Batman (Weldon 216). Joel Schumacher's 1997 Batman movie Batman Forever, the film that introduces Robin to the then-current Batman film franchise, portrays the character in a way that perhaps barrels into queerness rather than subtly linking or hinting at it (Weldon 205). Historically, Batman has been related to interpreting his relationship with Robin as sexual and/or romantic (Weldon 55) and when the canon hints at this relationship, nerds react poorly (Weldon 70). A queer or queer-coded Joker is necessary to nerds because of the way that the character contrasts Batman's prominently displayed and supposedly unflinching hypermasculine heteronormativity. A queer Batman, however, would shatter expectations of the character and stop him from being comfortably relatable to the fans. This is seen in the negative fan response to Joel Schumacher's Batman films where the relatively explicit queerness of the characters ${ }^{23}$ was cause for nerd outrage and backlash to the point where Schumacher was never again associated with the Batman franchise. Nerds simply cannot handle the idea of a queer Batman (Weldon 206-7) and that is why the fans want the Batman - and the heteronormativity he represents- to always win as a queer fear of Joker is a fear that the Joker will win - not by killing Batman but by turning him.

\footnotetext{
${ }^{23}$ Weldon describes Schumacher's Batman Forever casting call for Robin as "a palpable shift in the Dynamic Duo's dynamic - from a father and his son to leather daddy and his piece of rough trade" (Weldon 205).
} 
Queer Clowning - The Joker, "Dark Camp," and Performativity

In “'Why so serious': Cripping Camp Performance in Christopher Nolan's The Dark Knight," author Cynthia Barounis discusses the concept of "dark camp" in relation to the Joker, focusing on the character's crimes as literal performance art. At one point, Barounis compares Heath Ledger's role in Brokeback Mountain (calling it “a certain kind of attempt to convince straight people how nice gay people are") to the actor's later performance as the Joker. Barounis writes that the "Joker does not desire equal rights; instead he desires queerly sexualized forms of violence" (313). It is that excessive desire for violence, the way that he has historically goaded Batman into fulfilling apparently sadomasochistic urges, that Barounis connects back to what can only be called "dark camp". The use of dark camp over other aspects of camp (including Barounis' own "disability camp") in this section of the paper hinges on what "dark camp" has come to represent. While "dark camp" appears to have originally been coined by Kathryn Bond Stockton to refer to the relationship between race and camp in her book Beautiful Bottom, Beautiful shame: where "Black" meets "queer" (213), Stockton's term has been adapted by Barounis and by Lokeilani Kaimana in her article "Thoughts on Dark Camp" where she calls it "a scarring, as opposed to a citation, of time; it scars as it wallows in a problematic space for just a bit too long" (Kaimana). The Joker embodies the scarring, problematic "dark camp" Kaimana refers through how the character's portrayals are linked into displays of sexual aggression, ableism, problematic humor, and frequent transmisogyny. ${ }^{24}$ Dark camp, like camp itself, is linked intimately with performance and

${ }^{24}$ Many times, the Joker's feminine presentation is met with disgust that the text plays off as a joke. 
performativity. ${ }^{25}$ However, the purpose of dark camp, according to Kaimana, appears to be to unsettle the viewer (Kaimana). The Joker's "dark camp" serves up a canonical alternate version of the bright and cheery pop-art inspired Sixties Batman series that made the queerness of camp and Batman inextricably linked despite the industry's best attempts to separate the two. In this section of the paper, I aim to answer two questions: How queer performativity (Sedgwick 1) ties into the literal performances that the Joker puts on as the "Clown Prince of Crime" and what role, if any, camp plays in this aspect of the Joker's personality and presentation throughout his various appearances across the Batman comics canon.

Integral to discussions of the Joker's performativity is the role that "camp" in its original form(s) plays in his characterization as well as the connection between camp and the type of queerness of the character represents. In Andy Medhurst's "Batman, Deviance, and Camp," he writes that "trying to define camp is like attempting to sit in the corner of a circular room" (Medhurst 154), referring to what he sees as a futility in attempting to ascribe a firm definition to the term. Instead of attempting to coin a firm definition of camp, Medhurst chooses to refer to it as possessing/ referring to "a playful knowing self-reflective theatricality" (Medhurst 154). Here, at least one significant component of camp can be considered a theatricality that then be linked to performance/performativity. But I argue that, while the Joker's character embodies theatricality and the mutability/multiplicity of his identity throughout the decades lends him a Lady Gaga-esque ability to be everyone and no one simultaneously, the concept of

\footnotetext{
${ }^{25}$ Performativity here refers to Judith Butler's conception of performativity as repetitive actions that take on a ritualistic sense which then become performativity - someone performing gender/queerness/etc.
} 
camp can be teased open further to incorporate the Joker's shifting identities and how the clown persona has been queered in the process of creating the character. ${ }^{26}$ This reintroduces "dark camp" which can generally be considered funny in the way that "gallows humor" is: subversive when made by the person whose neck is in the noose, but a tool of cruelty when made by the person executing them. In this case, the Joker is very much a figure of cruelty, and looking at the character through the lens of dark camp shifts some of the character's over-the-top and violent behavior into place as the Joker, despite many attempts to portray him otherwise by the text and audience alike ${ }^{27}$, is far closer to the executioner than he is the person in the noose as the Joker is all but immortal ${ }^{28}$. In the comics industry, "camp" is frequently linked with an almost shameful notion of "silliness". ${ }^{29}$ There is nothing "silly" about the Joker and his current incarnations.

A key aspect of the discussion in this section is what queer performativity and dark camp look like in the Joker's characterization. For this, we return to Arkham Asylum: A Serious House on Serious Earth. As with The Dark Knight and The Killing Joke, Arkham Asylum is presumed to take place in an alternate version of the main

\footnotetext{
${ }^{26}$ It's interesting to note that Medhurst calls the use of camp in the Joker's Eighties characterization "the cleverest method yet devised of preserving Bat-heterosexuality" (Medhurst 160).

${ }^{27}$ Several pieces of work attempt to give the Joker a tragic and frequently traumatic backstory that serves to explain the Joker's violence and instability. The Killing Joke makes the character a down on his luck comedian that loses his pregnant wife in an accident, Death of the Family makes the character's initial fall into acid Batman's

${ }^{28}$ The Joker has survived several "deaths" in comics as well as the removal of his own face prior to Death of the Family.

${ }^{29}$ Glen Weldon refers to the reaction that DC writer Chuck Dixon had in response to the campy 1960s series where he pummeled another classmate over the series. Dixon's reaction was shame and anger at the thought of the 1960s series being what non-fans of Batman saw of the character and he responded with anger (Weldon 71).
} 
Batman universe. Therefore, nothing in this comic should pull from or lead to characterization in the main universe. The Joker in Arkham Asylum, as referenced in previous sections of this piece, is a figure whose characterization hinges on such signifiers as a supposedly "feminine" style of dress and an unwavering fixation on an uninterested male in order to code him as queer - and therefore dangerous. He is also a character who puts on a particular show in order to get the Batman - and much of Gotham City aside - to do what he wants. The Joker, in Arkham Asylum, is more akin to P.T. Barnum than Chuckles the Clown in this comic, but just because he has shifted the role of the clown to that of the ringmaster, that does not diminish the fact that the Joker never stops performing at any point in this comic.

Throughout the course of the Joker's almost eighty-year long history of appearances as one of DC Comics' most visible villains, he has never truly been the same character twice. (See Figure Three for several incarnations of the Joker across six decades.) Sometimes, even in the same book or film, the character takes on markedly different appearances, characterizations, or even identities ${ }^{30}$. For this section, I am going to talk about the mutability of identity in relation to the Joker's perpetual performance and how that relates to his queer-coding. I'll be looking at 2008's The Dark Knight where Heath Ledger played the character before his unfortunate and untimely passing as well as at Arkham Asylum and The Killing Joke as those works serve as the best examples of the way that the character's queerness - or queer coding - can be linked to his mutable

\footnotetext{
${ }^{30}$ In the 2008 film The Dark Knight the Joker takes the appearances of: a bank robber in a clown mask, a nurse, and a police officer in addition to his standard Joker look. Throughout that film, it is heavily implied that the Joker is always incognito.
} 
identity and his constant but inconsistent performances. These performances that link queerness with the clown person and are never the same performance twice are significant because even with the fluid characterization that the Joker has become known for, those are two of his most significant and harmful character traits. Judith Butler calls performativity "repetition and a ritual" (Butler xv). as the performance - people performing gender or sexuality in particular -- is not a single act or moment, but unconscious behaviors or actions done repetitively until they take on a ritualistic air. One way that Butler's definition of performativity becomes relevant to the Joker's incredibly fluid identity and characterization throughout the decades is seen in "Lady Haha: Performativity, Super-sanity, and the Mutability of Identity," where author Eric Garneau writes that:

What makes the Joker so interesting, though, is that unlike other characters who possess his longevity - whose new iterations often have to clumsily maneuver around or outright ignore previous models - the Joker actually thrives on supposedly irreconcilable characterizations. (33) These "supposedly irreconcilable" characterizations (some of which are seen in Figure 3) allow the texts to incorporate aspects of previous Jokers at will - or to pretend that these earlier clowns are not relevant anymore. For example, the Joker in the 2017 blockbuster hit Lego Batman is not the same Joker that appeared in the Sixties television series or the dark works from writers like Miller and Moore. However, he draws from them all the same, even from forms of media that should not be palatable for the children that make up the film's preferred audience. The Joker in Lego Batman comes practically pre-loaded 
with several of the same behaviors that previous Jokers have. ${ }^{31}$ In the same vein, across the comics, the Joker has become a chimaera made up of the various and often conflicting characterizations that his character has had across the years (Hassoun 3). Ever present, as I have argued in previous parts of this thesis, is the consistent use of queer signifiers to code the character as queer in a genre that has little positive representation for queer readers. Seeing that this use of queer signifiers is largely and frequently connected with the Joker and Batman relationship and the symbiosis that is present across multiple incarnations of the character's existence, this coding is perhaps the single constant in the mutable identity that many creators working on the Joker seem to bestow upon him. Briefly, let us look at some of the various aspects of the flexible identity that are seen in different incarnations of the Joker and how many of these identities use this queer performance throughout to signify his specific evilness.

\footnotetext{
${ }^{31}$ In Lego Batman, the Joker embodies aspects of the Joker in previous incarnations. The character's makeup looks similar to that of Cesar Romero's in the 1960s Batman series, he uses the complex manipulation present in the Jokers of Batman the Animated Series and The Dark Knight in facilitating his final plan, and a core theme to his characterization in the film is a possessive desire to be Batman's "main villain", the film purposefully using the language of love and desire in their conversations and monologues, that reads like a milder form of the dialogue present in Batman: Death of the Family.
} 

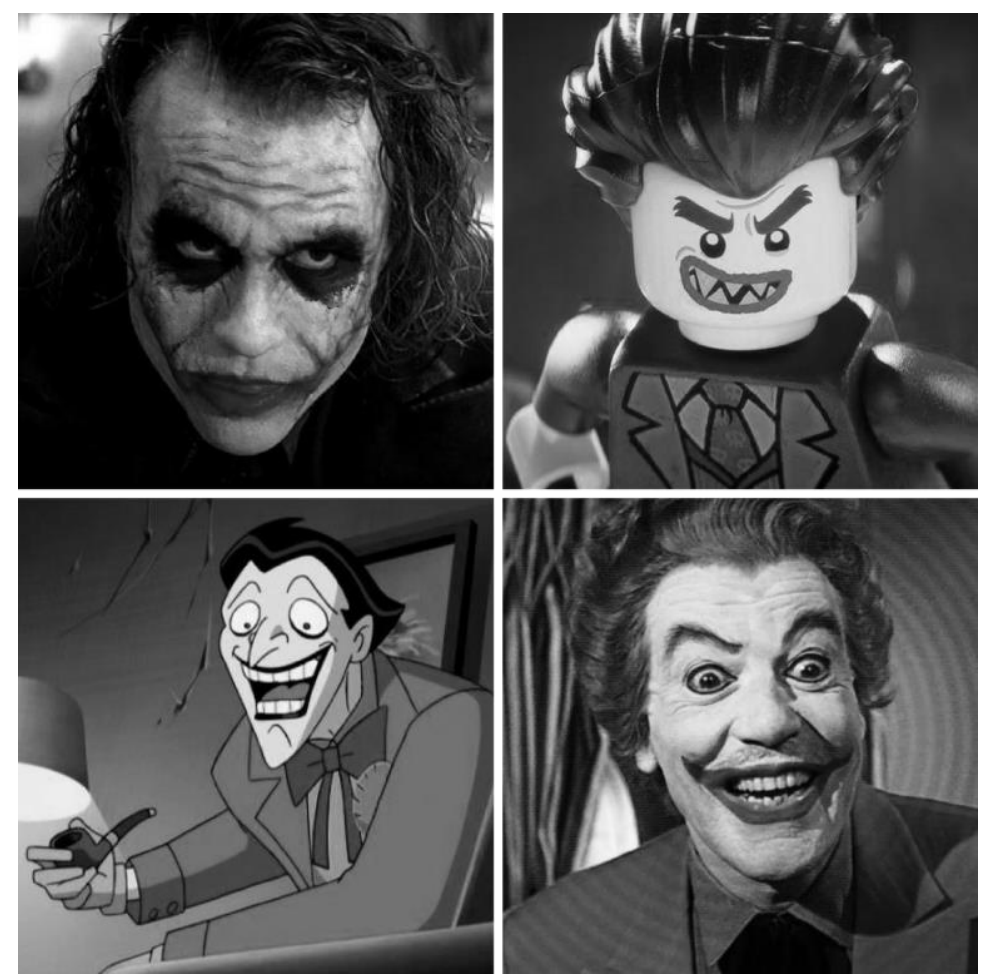

Figure 3 - From left to right, clockwise: Heath Ledger's Joker in The Dark Knight, the Joker in The Lego Batman film, the character (voiced by Mark Hamill) in Batman Beyond: Return of the Joker, and Cesar Romero in the 1960s Batman series.

The text of The Dark Knight Returns creates a Joker whose performer status hinges on queer performance- take for instance, a scene in the film where the Joker is dressed in a nurse's outfit and is seen skipping away from a hospital as it explodes. The Joker present in The Dark Knight Returns is a performer from his first appearance, performing a twisted take on the circus clown routine (closer to Steven King's creepy clown in It than the Joker's original incarnation) and in one scene putting on makeup to prepare for a television appearance to prove that he is cured of what ails him (Miller 
121). The character's clownish, nightmarish take on queerness ${ }^{32}$ is one that that exists to threaten both Batman and his readers. In Arkham Asylum, the Joker becomes the Virgil to Batman's Dante (Garneau 39), taking the stage as Batman's guide to the underworld that the asylum represents. Then in The Dark Knight, arguably one of the most interesting portrayals of the character in recent years, the Joker's various identities collide, not just in his revolving stable of costumes, but in his ever-shifting backstories (Garneau 43).
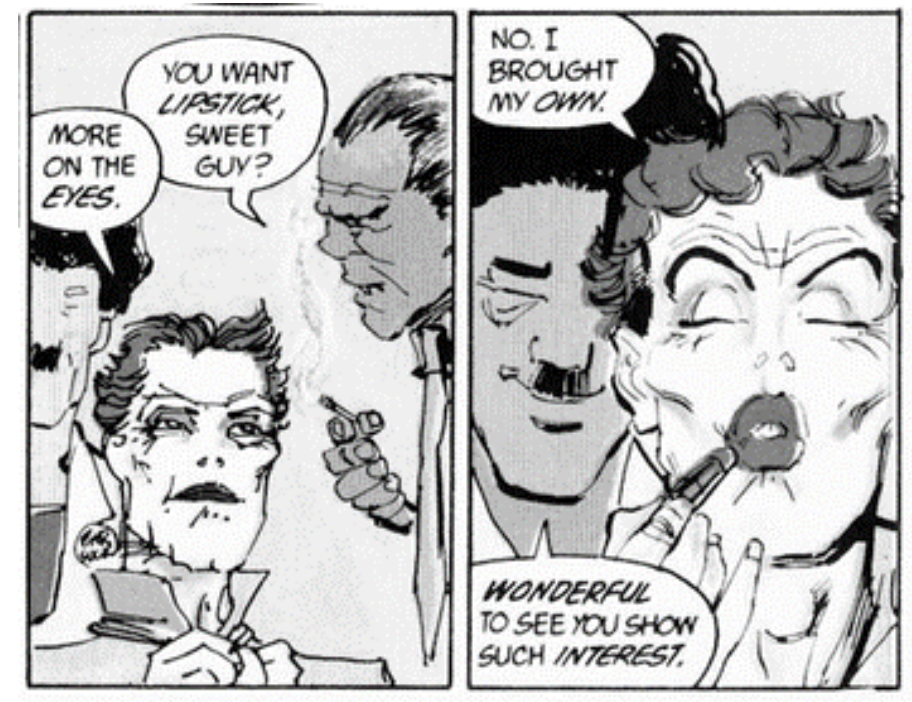

Figure 4 - A set of two panels from The Dark Knight Returns

One aspect of queer performativity present in Joker, particularly in The Dark Knight, is the way that the character tailors his appearance and behavior depending on his audience - while remaining recognizable as the Joker. This is reminiscent of the way that queer people have to shift their identities, presenting and performing in a way that is tailor-made for their interactions with distinct groups of people in order to protect

\footnotetext{
${ }^{32}$ As evidenced by the way that the Joker's queer-coding in The Dark Knight returns is linked explicitly with acts of monstrosity. In his next appearance, after putting on his own lipstick and pursing his lips for the "camera", he proceeds to murder dozens of people in a live studio audience.
} 
themselves from harm. The Joker's multiple shifts from "simple" criminal to mastermind to nurse, complete with several different backstories is akin to the mutable identities that many queer people adopt depending on their surroundings. The thing about the Joker and his various queer performances across the decades is that nothing in these texts show that he believes in any of what he is doing. The character is always playing a part and he is in deep. Because of the character's flexible, fluid identity and the fact that he is always ready to adopt at a moment's notice, he is the perfect method actor. However, what makes this significant and problematic is the way that the incorporation of his particular brand of performance pushes forward

\section{Conclusion}

The Joker is a constant in both the Batman mythos and the comic book fandom. Even though the character has been killed off or benched in numerous timelines and texts, it remains doubtful that the Joker will be anything other than immortal. For almost eighty years, the Joker has been a continually villainous presence in the Batman's life, one that comes along with a significant amount of baggage. The Joker is a character who is almost as big a household name as the Batman and that means the subtle and not-sosubtle aspects of his queer coding have been present in the different versions of the character over the years. Throughout this paper, I have noted that these various texts have utilized harmful misconceptions about queer men to put forward their idea of the Joker as a character whose queerness is subtle, constant, and a threat. In his interview with Christopher Sharrett, Frank Miller seems aware of the queer signifiers present in The Dark Knight (Joker wearing lipstick, calling Batman “darling”) by calling his approach to 
portraying to portraying the character a "sensible and interesting" way (Sharrett 37).

While Miller also appears to understand the problematics of his take on a queer (coded) Joker in a period where gay men were persecuted ${ }^{33}$ and stereotypes about their sexuality were present across mass media, he never apologizes for it in the interview. As recently as 2017 and the Lego Batman film, the Joker has shown up in non-comic works with the familiar queer-coding attached to his characterization. Played for laughs, this characterization does not show queerness and queer villainy in any way resembling respectful a portrayal. This characterization is largely unaddressed by the text or its various creators, being seen as a natural part of the Joker's characterization and one that doesn't need to be analyzed. While queer villains are not necessarily a problem if developed in a way that acknowledges the history of queer villainy and refrains from relying on historical and harmful stereotypes, the Joker has yet to be portrayed in such a way. This means that his popularity serves as a vehicle for problematic portrayals of queer men and queerness that have existed for several decades and now, with the rise of film adaptations of existing comic properties, has the potential to reach an even wider audience, one that will consume this queer-coding uncritically. Queer representation in superhero comics is one form of representation that has been sorely overlooked. Using queer coding for villainous characters like the Joker, unfortunately, is the closest that many of these comics come to providing necessary representation to queer readers. While books like DC Comics' Batwoman and the recently canceled Iceman series at Marvel have centered queer characters, these books are not marketed in the same way that

\footnotetext{
${ }^{33}$ This would have been around the same time that Matthew Shepherd was murdered in a homophobic hate-crime and while queer sexuality was still largely criminalized in Western countries.
} 
"iconic" Joker stories have been and do not get half as many market opportunities to appeal to queer audiences. When trying to solve the problem of a queer coded Joker and what this sort of shallow and problematic representation means to queer fans of superhero comics, four main solutions stand out. First, the editors on superhero comics needs to educate themselves and their staff about what queer coding is and how it is incomparable to actual queer representation. Second, these companies need to make more characters explicitly queer rather than the sly nod of coding. Third, they need to start hiring more queer creators to work on these characters. Finally, these companies need to place more weight behind their decisions to queer characters, marketing widely and to audiences that perhaps have felt that superhero comics aren't for them because their representation has been limited to queer coded villains and one-off characters who are barely used before being written off. The industry needs to move away from queer coding villains like the Joker because, in 2018, queer coding the Clown Prince of Crime is not a good enough avenue to queer representation. 


\section{Works Cited}

Barker, Meg-John. Queer: A graphic history. Icon Books, 2016.

Barounis, Cynthia. ""Why so Serious?": Cripping Camp Performance in Christopher Nolan's The Dark Knight." Journal of Literary \& Cultural Disability Studies 7.3 (2013): 305-20. Web.

Benshoff, Harry M. Monsters in the closet: Homosexuality and the horror film. Manchester University Press, 1997.

Brooker, Will. 'Batman's Killing Joke, and Its 'Edgy' Rape Storyline, Is Not a Comeback I Want to See." The Guardian, Guardian News and Media, 15 June 2016, www.theguardian.com/books/2016/jun/15/batmans-killing-joke-and-its-edgystoryline-comeback-alan-moore.

Butler, Judith. Gender Trouble: Feminism and the Subversion of Identity. Routledge, Taylor \& Francis Group, 2015. Print.

Collins, Max Allan. "Did Robin Die Tonight?" Batman. Vol 1, No 408, DC Comics 1987.

Devine, Scott, director. Necessary Evil: Super Villains of DC Comics. Performance by Christopher Lee, 2013.

Dini, Paul. "Joker's Favor." Batman The Animated Series, season 1, episode 22, 11 Sept. 1992.

Dini, Paul, and Bruce Timm. The Batman Adventures: Mad Love. DC Comics, 1994. Print.

Doty, Alexander. Flaming Classics: Queering the Film Canon. Routledge, 2002. Print.

Doty, Alexander. Making Things Perfectly Queer: Interpreting Mass Culture. University of Minnesota, 1997. Print.

Erwin, Elizabeth. "How Horror Thwarted'The Code'." The Gay \& Lesbian Review Worldwide 22.6 (2015): 18.

Felton, Cosmo. "Batman in the 1980s" Lonely Gods. <http://www.lonelygods.com/w/bat4.html> Internet Archive. <https://web.archive.org/web/20170319044236/http://www.lonelygods.com/w/bat $\underline{4 . h t m l}>$ 
Garneau, Eric. "Lady Haha: Performativity, Super-Sanity, and the Mutability of Identity." Joker: a Serious Study of the Clown Prince of Crime, University Press Of Mississippi, 2016, pp. 33-48.

Halperin, David M. Saint Foucault: Towards a gay hagiography. Oxford Paperbacks, 1997.

Hassoun, Dan. "Shifting Makeups: The Joker as Performance Style from Romero to Ledger.".Joker: a Serious Study of the Clown Prince of Crime, University Press Of Mississippi, 2016, pp. 3-17.

Hutton, Zina. "Let's Stop Giving The Killing Joke More Credit Than It Deserves." Stitch's Media Mix, 23 July 2016, stitchmediamix.com/2016/07/23/letsstop-giving-the-killing-joke-more-credit-than-it-deserves.

Kaimana, Lokeilani. "Thoughts on Dark Camp Lokeilani Kaimana / FLOW Staff." Flow, 18 Aug. 2011,www.flowjournal.org/2011/08/thoughts-on-dark-camp/.

Medhurst, Andy. "Batman, deviance and camp." (1991): 149-163.

Miller, Frank, Klaus Janson, and John Costanza. Batman Noir: The Dark Knight Returns. DC Comics, 2015. Print.

Miller, Frank. "The Dark Knight Returns. 1986." New York: DC Comics (2002).

Moore, Alan, and Brian Bolland. The Killing Joke. DC Comics, 1988. Print.

Morrison, Grant. Arkham Asylum: A Serious House on Serious Earth 25th Anniversary Edition. DC Comics, 2014. Original scripts included.

Nolan, Christopher, et al. The dark knight. Burbank, CA: Warner Home Video, 2008.

Shiach, Kieran. "'The Killing Joke' Doesn't Deserve The Credit For Oracle.” ComicsAlliance, 26 July 2016, comicsalliance.com/killing-joke-barbaragordon-oracle/.

Sedgwick, Eve Kosofsky. "Queer performativity: Henry James's The art of the novel." GLQ: a journal of Lesbian and Gay Studies 1.1 (1993): 1-16.

Snyder, Scott, Greg Capullo, and Jock. Death of the Family. DC Comics, 2014. Print.

Starlin, Jim, et al. Batman: A Death in the Family. DC comics, 1988.

Stockton, Kathryn Bond. Beautiful Bottom, Beautiful shame: where "Black" meets “queer”. Duke University Press, 2006. 
Sullivan, Nikki, and J. R. Cadwallader. A Critical Introduction to Queer Theory. Edingburgh UP, 2014. Print.

Taylor, Tosha. "Kiss With A Fist: The Gendered Power Struggle of the Joker and Harley Quinn." Joker: a Serious Study of the Clown Prince of Crime, University Press Of Mississippi, 2016, pp. 82-93.

Weldon, Glen. The Caped Crusade: Batman and the Rise of Nerd Culture. Simon \& Schuster Paperbacks, 2017. Print.

Wertham, Fredric. Seduction of the Innocent. New York: Rinehart, 1954

Wilde, Jenee. "Queer Matters in The Dark Knight Returns: Why We Insist on a Sexual Identity for Batman." Riddle Me This, Batman!: Essays on the Universe of the Dark Knight. Ed. Kevin K. J. Durand and Mary K. Leigh. McFarland, 2011. N. pag. Print.

Wright, Bradford W. Comic Book Nation: The Transformation of Youth Culture in America. Johns Hopkins UP, 2003. Print. 